\title{
Change as a Thematic Code in Chaos theory in relation to the Bakhtinian Carnivalesque.
}

\author{
A Critical Research. \\ Submitted by Yara Eid Abu El-Manni. \\ Under the Supervision of Prof. Ahmed Aboud.
}

\begin{abstract}
Chaos theory shares a common critical ground with the Bakhtinian Carnivalesque which is the literary phenomenon of change. Such a controversial aspect goes through three main consecutive phases that crystalize the ever-changing development of a literary text. These stages begin with the high sensitivity of the masterpiece to the initial change and how far a small event or an unpredictable scene could control as well as reverse the rest of the literary work. Moreover, this nonlinear dramatic change stands as a means of subversion so as to challenge the static norms and the fixed social, political or religious rules in a community. Indeed, this chaoticcarnivalistic subversion would give a way to the readers as well as the critics to question the rustic ideologies and cast light on other paths for rebirth and salvation. Therefore, change serves as the author's master guide towards the literary dynamic regeneration for elaborating and renewing what used to be considered changeless and consistent.
\end{abstract}

Key Words: Chaos theory; Bakhtinian Carnivalesque; Change; Subversion; Regeneration

The Butterfly Effect and the Bakhtinian Carnivalesque: A Theoretical background.

The Origin of Chaos Theory, and the Butterfly Effect.

It all started when Henri Poincare (1854-1912), a French mathematician, made an impressive realization which is that the slightest minor change in the initial state of one of the bodies can cause a drastic change in its predicted path. This is called the sensitive dependence on initial conditions which is the main principle as well as an alternative 
term for Chaos Theory. Many years later, the American meteorologist and mathematician, Edward Lorenz (1917-2008), during setting differential equations to predict the weather, he discovered that if he ran the calculations starting from an extremely slight difference between them, the trajectory of the outcomes will be completely different. That was when his attention was drawn to chaos theory. Later, he wrote a paper about the butterfly effect which became the figurative synonym and the most popular symbol of the chaos theory.

Since then, the public interest in this theory started building up, according to Gordon E. Sleuthing in his book Beautiful Chaos (2000):

Chaos in this original usage suggests randomized energy with potential for growth and order. Although in contemporary nonscientific usage "chaos" has come to denote confusion and disorder, in contemporary understandings of science the word has an affinity with the original Greek: it suggests the paradoxical state in which irregular motion may lead to pattern and disorder and order are linked. (xxiii)

Moreover, Chaos theory is a scientific evolutionary term that refers to the lack of order, systematization or arrangement. It has been used by scientists to examine and explain randomness and unpredictability, regarding scientific phenomena and experiments. As a scientific theory, it focuses on how an extremely minor change could lead to unexpected huge outcomes; which is referred to as the Butterfly Effect or the high sensitivity to the initial conditions. In accordance with what is reported in the online website of Saylor Academy "Saylor.org", "While chaos theory emerged out of mid- to late-twentieth-century speculative mathematics, it 


\section{Yara Eid Abu El-Manni}

has also had a remarkable impact upon both the social sciences and studies in the humanities over the last three decades" (1).

Thus, the present study discusses the origin of this revolutionary theory and what it is all about, highlighting its scientific-based background. Furthermore, it implies the extra dimensions and representations of the Butterfly Effect, concerning a meta-critique of the literary interpretations of chaos theory throughout multiple perspectives. Besides, since Lorenz is credited with the discovery of the Butterfly effect, he touches on how this innovative theory could be defined as the lack of a specific pattern, unpredictability and the inability to predict the future moves. So, chaos theory exists whenever there is nothing but irregular randomness and absence of determinism:

I had come across a phenomenon that later came to be called 'chaos' - seemingly random and unpredictable behavior that nevertheless proceeds according to precise and often easily expressed rules. . . I shall use the term chaos to refer collectively to processes of this sort - ones that appear to proceed according to chance even though their behavior is in fact determined by precise laws. (Lorenz ix-4)

For the Butterfly effect, the idea of a butterfly is originated from the shape of the Lorenz attractor (see Figures 1) which looks like a butterfly. In fact, the question "Does the flap of a butterfly's wings in Brazil set of a tornado in Texas?" is just a figure of speech said by Edward to clarify the extent of sensitivity on initial conditions. Originally, Lorenz used to use the sea gull as a symbol for the sensitive dependence, he first presented this term in 1972 meeting when he noted that the flap of a butterfly's wings in Brazil may set off a tornado in Texas. That switch was made due to "Perhaps the Butterfly, with its seeming frailty and lack of power, 
is a natural choice for a symbol of the small that can produce the great" (Lorenz 15) or how a trivial factor could create a great curve in the futuristic events.

Similarly, Lorenz in his book The Essence of Chaos, mentioned how George R. Stewart, in his novel Storm, supposed how " a man sneezing in China may set people to shoveling snow in New York"(15). This indicates that no matter how unimportant an event may seem; it could be the reason beyond a chain of the coming huge results:

For many years, Ed Lorenz thought he had discovered the mathematically simplest system of ordinary differential equations capable of producing chaos. His equations became a paradigm of chaos, and the accompanying strange attractor, which serendipitously resembles the wings of a butterfly, became an emblem for early chaos researchers. (J.C Sprott 1)

Besides, the Butterfly effect theory is a multi-dimensioned theory, which can take the lead in various fields, because what chaos theory manifests is that it re-explains what is proposed in an infinite cycle of tendencies beyond the scientific interests; political, social, literary, etc. This, in fact, makes chaos theory a flexible not a strict criterion to take in any spotted piece of work. Similarly, Pamela Gossin focuses in Encyclopedia of Literature and Science (2002), on how far "chaos theory is an umbrella term that encompasses a series of interrelated developments in mathematics and many branches of the natural sciences. Its historical roots lie in the late nineteenth century" (72). One of these disciplines influenced by chaos theory is the twentieth century literature, which can be better analyzed and discussed by adopting the butterfly effect (BET) as a method of literary interpretation. 


\section{Yara Eid Abu El-Manni}

So, this high profile argument is the ultimate interest of the present researcher who hypothesizes that chaos theory does not only work as a mere scientific theory, but also can make sense as a contemporary process to anatomize and decode both the implied chaotic as well as the explicit ordered information given beyond the lines in a literary text. That is what Jo Alyson Parker attempts to illustrate in Narrative Form and Chaos Theory in Sterne, Proust, Woolf, and Faulkner (2007), by pointing out that "Our inability to predict precisely the evolution of a chaotic system is due to its sensitive dependence on initial conditions, whereby 'microscopic perturbations are amplified to affect macroscopic behavior'the so-called butterfly effect" (9-10).

As a matter of fact, the literary reception of chaos theory gives the literary texts a chance to gain new dimensions and interests. So, analyzing a text from the literary BET perspective broadens the reader's perception throughout non-linear differential equations, depending on the initial event "the essential catalyst" that ignites every single out -coming action. Likely to what Slethaug argues:

Since art is a means of imposing order upon experience, it puts under erasure, as Derrida would say, all the flux and nonlinearity that constitutes life, but then reinscribes it through narration...it is surely chaos theory that can help to explore, if not entirely explain, the mysterious and complex in narration, culture, and life. (xv)

In this respect, it indicates how the trajectory of any story becomes unstable due to the remarkable changes introduced by its author, so the literary masterpiece turns into a less predictable and more complicated one. This gives the chance to modern literary theorists and contemporary analysists to delve deep and bring distinguished ideas out of the text to 
the surface; throughout rediscovering a literary text by studying the dramatic change as an overwhelming feature along with its reasons and consequences. Literary speaking, in a masterpiece, when an event is altered or a character suddenly interferes with an unpredictable behavior; these initiative changes would slide down and trigger off multiple consecutive fluctuations that are different in their significance and preference in a literary work.

This scientific literary description clarifies how the sensitive and multitasked BE stands as an evolutionary theory when it is employed as a method to approach and deliver literary texts. Consequently, the representation of chaos theory as a literary technique proves how chaotic change impacts the author's imaginative skills and fulfills the needs of the literary critics in various ways:

As a literary theory, chaos theory helps readers more deeply understand and appreciate the complex ideas behind some works of literature we might encounter. For example, the application of chaos theory to a novel... reveals a deeper exploration of reality and human identity than critics and readers had previously realized. (Saylor 1)

This gradually results in defining literary texts are chaotic systems, where there is no absolute criterion, which supports the claim that chaos theory stands as a method for analyzing fictional texts. This gives a great chance of understanding the literary system once the author breaks all the certainties and makes the reader goes through literary waves of change that draws further analysis of the text:

Chaos theory enables us to see the physical world in new ways and to look anew at texts that I call "chaotic". By viewing such texts through a chaos- theory lens, we can link 
narrative structure with narrative content and link the formalism of traditional narratology with the reader's production of narrative meaning. (Parker 2)

This answers the question if the Butterfly Effect could serve as a literary theory since it actually helps the reader to acquire and embrace all the changes that take place in a text. Besides, in his Philosophical Essay on Probabilities, P.S Laplace throws light on the infinite cycle of changes and effects, as he believes that one has to consider the present moment as a repercussion of the preceding one and the mainspring ground of the following. So, only one minor occasion can start it all the suspension and the subversion in all sides of a society reflected in a literary work. Similarly, Etienne Ghys in "The Butterfly Effect" suggests that the "underdog events" or the minor disturbing variations could control the rest of the mainstream.

So, chaos theory would stand as a literary technique to tackle change as a phenomenon throughout exploring the progressive aspects of change that happen in order; beginning with the high sensitivity, going through a subversive nonlinearity and leading to the dynamic regeneration of the text understudy. These chaotic features of change are common between the butterfly effect and the Bakhtinian Carnivalesque. such surprising changes in the events result from the nonlinear twist that occur all over the literary narratives. Moreover, the sensitive dependence on the initial conditions elucidates how in a literary work, one unpredictable and challenging change would be considered as a new seed for another following change in the text. Adding to this, adopting the butterfly effect as a method of analysis would boost the critical interpretations of the text, since "the application of chaos theory has been broadly applied to many non-scientific academic fields" (Lorenz 10). 
Thus, a chaotic literary analysis shows that once a masterpiece fosters a myriad of sudden changes, these changes would counter and violate the dominant criteria and render the oriented spirit of the work throughout revolutionizing multiple ethics and expectations, as "it is well known that a chain of events can have a point of crisis that could magnify small changes. But chaos meant that such points were everywhere...sensitive dependence on initial conditions was an inescapable consequence of the way small scales intertwined with large" (Gleick23). Thus, the literary freedom and the spirit of change are mainly sprouted out of a simple event that broke the tone of the determined supreme laws.

On the other hand, the literary mobility that is molded as a result of the effective milieu of the initial events is also evident and accumulated as a dramatic feature of the Bakhtinian Carnivalesque. According to the online Oxford reference, the term of the Carnivalesque mainly refers to how Mikhail Bakhtin used this term to describe the literary work that "depicts the de-stabilization or reversal of power structures, albeit temporarily, as happens in traditional forms of carnival" (1). Likewise, the most prominent principles of chaos theory which are the sensitive dependence on initial conditions, subversive nonlinearity, and the dynamic regeneration meet along with the basic criteria of the Bakhtinian Carnivalesque (BC) that highlights the theme of change, which can be considered a controversial recurrent idea that dominates both theories on a literary ground.

This hypothesis would elaborate how a work of art that reflects unexpected changing notions can be received on a chaotic- carnivalistic basis. Besides, the combination between the cores of the two controversial theories is going to be crystalized throughout delving deep into the chaotic features of the carnivalistic language and imagery, in 
addition to discussing how far the nonlinear anarchy of the Butterfly Effect is reflected beyond the carnivalistic approach of a literary work. Thus, Michaeline A. Crichlow and Piers Armstrong, in "Carnival praxis, Carnivalesque strategies and Atlantic interstices", highlight the history of the Bakhtinian Carnivalesque and how its ancient roots are based on the theme of change:

In medieval times, carnival was part of an organic cycle of discipline and liberation. For a day the fool or the fattest glutton in the town became 'king', and, to a lesser extent, or at least by implication, the 'king' became a 'fool'... carnival was politically useful to the powerful as a harmless escape valve for oppressed people. It was, nevertheless, predicated psycho-socially on a symbolic inversion of status which is highly ambiguous. (4)

So, paralleling the Butterfly effect with the Bakhtinian Carnivalesque could stand throughout their nonlinear and ambivalent characteristics: the dependence on the initial conditions, the subversive nonlinearity and the dynamic regeneration, which could be the common phases of change between the two theories. Thereafter, this research focuses on change as a mutual literary phenomenon within an applied critical study on some selected works that go through these hypothesized stages of change and the main mutual characteristics of the Butterfly Effect and The Bakhtinian Carnivalesque.

The Carnivalistic / Chaotic change:

The theme of change is a recurrent issue for both theories. For the Butterfly Effect, it focuses on how an initial change or an unpredictable incident could lead to immense consequences in a chain reaction afterwards. In this respect, some interior changes take place in chaotic 
cycles all over a literary text when one ripple succeeds to cause large consequent switches afterwards. Similarly, the Bakhtinian Carnivalesque sheds light on the constant unexpected changes and renewal against the strict modeled patterns; as every single angle in the literary carnival does matter, since it could turn the whole system upside down. In a carnival, there is a change in every corner. A pauper can dress as a king, a nobleman can be a clown, etc. Such a change can bring an extreme alteration in the social strata and morale. Hence, these individual changes make everything else overturned in a literary text; the character's costume, language, behavior as if another symphony of communication is created among the people in a chaotic carnivalistic atmosphere. Regarding Bakhtin's literary Carnivalesque, a character could ignite a revolting change, when $\mathrm{s} / \mathrm{he}$ does not mingle within the social authoritative system.

Both the Butterfly Effect and the Bakhtinian Carnivalesque celebrate change and the infinite possibilities of reordering life at all levels, by destroying the barriers and authoritative codes created by hierarchies replacing it with a vision of mutual cooperation and equality. In other words, the goal of the chaotic carnivalistic system is gaining freedom and equality which are the highest ideal aims of human existence. Apparently, both theories reject all kinds of stereotyping and domination; as for the carnival sense of the world, it suggests and implies unexpected shifts and changes all over the literary text, liberating from the solid norms and the regular boundaries, which asserts the chaotic" free-floating spirit of carnival"(Benzi Zhang 35). Besides, the carnivalistic literary analysis focuses on the idea of the regenerating transformation, represented by the constant joy of change and the unusual resistance to every stable rule in the name of the chaotic rebellion. For 


\section{Yara Eid Abu El-Manni}

the Carnivalistic change, it seems to stand as covering or labelling an idea with another on a chaotic basis to encourage the readers to begin an unexpected quest so as to get what is beyond the worn masks. Thus, it is worthy to mention that for the $\mathrm{BE}$ and $\mathrm{BC}$, one slight sudden change in the text could lead to a serious of unpredictable and non-linear events; so this kind of literary ambivalence against the expected norms creates an anarchic carnival spirit in the work; leading the readers to enlightenment.

Thus, change happens hand in hand not only with the Bakhtinian Carnivalesque (BC) but also with the Butterfly Effect (BE), since one of the mutual valuable chaotic aspects between them is the high sensitivity to the initial conditions. This feature implicates how once a destabilized opening event takes place, it causes scattered constellations of affected incidents. This creates a literary text with dependent nature of being controlled by what happens first. So, the authority in a literary text goes back to the primary change undermined within the ambivalent subversion that happens consequently in the text and disturbs the following incidents whether directly or indirectly. Besides, the carnivalistic sense of liberation and humor drive the text into multiple rebellious directions, which enriches the work with a festivity of unpredictable forces concerning, not only the irregular track of events but also the dicey behavior of the characters and their changeable language and costumes used in a carnivalistic mood amidst the events, "Bakhtin extols carnival as the true feast of time, the feast of becoming, change and renewal" (Anusha Ramani 2). What is implicit in this view is the assumption that the carnival's changing force seems to be reflected in the renewal spirit among the lines and the events of the text. So, the literary change could be perceived "where all conventions are abandoned, hierarchies 
transgressed, and physical intensity is celebrated" (Doris Weichselbaumer $6)$.

That is why the present researcher casts light on the power of change all over the literary work because it helps to get to the deeper thoughts of the author. In addition to the uncovering of the complex layers of the masterpiece by analyzing the unprepared and awkward disguise of some characters throughout acting in an illogical manner or not dressing like themselves properly. Nothing is precise anymore. So, "nothing is taken for granted and instead concepts have the ambivalence of carnival" (Paul Sullivan et al.4). Hence, the text becomes submerged in unpredictable but meaningful chaos, which represents the main core of the literary Carnivalesque. Over and above, focusing on change as a master identity of the Bakhtinian Carnivalesque entails investigating the carnivalistic reliance on the early coincidence in a literary text. Furthermore, the anarchic introducing of the events and the disorderly fragmented scenes arises the rhythm of change, where the audience has no command but to get excited and eventually understands the key spirit of the masterpiece. Thus, the Carnivalesque evokes an authentic and realistic critique by not copying a safe literary version of what is rooted and previously rigid. It is meant to:

Force readers to experience the instability of character and identity, to grow fearful of everyone and everything no matter how deeply one needs to believe in something. A magical realist world is full of incompetent guides, intangible powers and laws, partial gazes, camouflages and disguises, endless exile, processual identities, inexplicable terror, lies, spies, metaphors, decay. People are never just 


\section{Yara Eid Abu El-Manni}

themselves, they are composites; there are no essentialist categories, only hybrids. (Mady Schutzman 11)

Thus, the literary festive inversions and the sudden alterations in a piece of work teach the reader and the critic a lot about the carnivalistic-chaotic writing throughout detecting the changing aspects.

The chaotic aspects of the carnivalistic grotesque realism:

One of the carnivalistic main terms is the grotesque realism that is filled with the chaotic changing spirit. The Bakhtinian grotesque basically refers to the degradation and the discrowning of all that is high, spiritual or abstract. Speaking of the anarchic grotesque realism, Bakhtin in Rabelais and his World (1965) elaborates that "it frees human consciousness, thought, and imagination for new potentialities. For this reason, great changes, even in the field of science, are always preceded by a certain carnival consciousness that prepares the way (49). Also, regarding the Bakhtinian grotesque, Dentith investigates how it reflects the characteristics of folk art and anarchy in a mixed dichotomy of unbounded transformations to express the outcome of a liberated society. Moreover, "grotesque realism can be here seen as a kind of an artistic practice which moves both from the upper to the lower level of the biological body and from heaven to earth; indeed, these movements are equivalent"(Dentith 78). Moreover, change is born with the assistance of the carnivalistic laughter and degradation from top to bottom of the text.

This humorous uncrowning is contagious; once it begins at a scene, it affects the subsequent line of performances. In other words, the literary laughter presents many answers as well as justifies multiple changes in the work. So, an author's supreme purpose of adapting the carnivalistic essence is generally to destroy the fear of the unchanging and the deadlock writing. Thus, the author tends to refuse the literary limitations 
by ignoring the moral patterns. This leaves the readers free to decompose and criticize the fixed literary, social and cultural customs. In "Postcolonial Literature and the Curricular Imagination: Wilson Harris and the pedagogical implications of the carnivalesque", Cameron McCarthy and Greg Dimitriadis reveals that Russell McDougall points out how a carnivalistic text is characterized by anything and everything that could revolutionize the text and help change finds its way beyond the lines:

For McDougall, carnivalesque fiction tends to be distinguished by the following features: (1) satire, parody, laughter, and extraordinary inventiveness of plot; (2) Socratic settings of truth and discovery in dialogue; (3) inserted genres of philosophical speculation, oratorical speeches and other normatively 'non-fictional' discourses; (4) a mock-heroic protagonist whose experiences and adventures are presented as an allegorical exploration of a larger system of political or cosmic forces; (5) characters who are in a constant state of flux, fragmentation, or decomposition; (6) reversibility of fiction in which characters' fortunes and roles are as interchangeable as a set of masks; (7) cumulatively, a peculiar sense of doubling or mirror distortion of the polyglot characters that inhabit the novel. (qtd. in McCarthy \& Dimitriadis 5)

In addition to these carnivalistic features, the carnivalesque grotesque transgresses all limits to blossom a rebirth and an equal criteria and a productive change. Thus, one can hypothesize that the Bakhtinian grotesque adopts chaotic principles which are the dependence on the initial events, the nonlinear subversion and the dynamic renewal, so as to 


\section{Yara Eid Abu El-Manni}

create brand new visions in literary texts. This process takes place through challenging the strict morals and the expected stream line of events.

Hence, the transgressive qualities of the carnival confirm how a carnivalistic work carries on an anarchic identity. Additionally, this proves the idea that the Butterfly Effect and the Bakhtinian Carnivalesque are two sides of a coin; in the way they change the proposed ideologies and the disciplinary hierarchical imposed laws. Then, a reader would notice that" Carnival contains a utopian promise for human emancipation through the free expression of thought and creativity" (Andrew Robinson 3). Hence, it is worthy to mention that both theories are based on their dependence on the primary changes as well as subverting the static state so as to create a liberated literary atmosphere. For John Francis Harty in Oscillation in Literary Modernism (2009), he relates the two theories closer by showing how applying a literary critique via $\mathrm{BE}$ and $\mathrm{BC}$ would overview the mutual joint between them which is adopting change as a critical device and a literary phenomenon, "Furthermore, the forces inherent to both the Butterfly effect and the Carnivalesque advocate the possibility of radical and accelerating metamorphosis" (159). On a chaotic -carnivalistic based approach, a critical thinking of the insights of a literary corpse indicates how the analysis of the literary change and its dominance could give a more adequate apprehension of the work. Once the high sensitivity impulse is exhibited in the text, the rapid change is immediately expounded.

In a nut shell, the present researcher regards change as a literary phenomenon and a dynamic characteristic that is apparent in the analysis and the application of the common traits between the $\mathrm{BE}$ and $\mathrm{BC}$ which are the high sensitivity to initial conditions, subversive nonlinearity and 
the dynamic regeneration. This manifests that each of these aspects of literary change could contribute to explicate and unravel the masterpieces via embarking upon the author's sharp bends of what used to be changeless and fixed by pushing various social, religious and political boundaries. This runs through dealing with how "the smallest part of a subsystem can affect and shut down the most carefully regulated and friendly attuned macrostructure (Slethaug, xix-xx), as any text is an interrelated network of invariables, and mapping out the eventual and influential messages beyond the lines of a literary text, since the persistent change produces distinguished critical remarks.

\section{The Sensitive Dependence on Initial Events}

The notion of the high sensitivity to initial events refers to how a dramatic primary incident that seems trivial at the very beginning of the literary work could lead to an infinite series of unfortunate events along the masterpiece. Furthermore, the dynamic literary events are mostly introduced and developed due to the least predictable scenes in a literary piece. That is why literary coincidences in a text could be classified into two main types; some are not certain, not planned and not important; these are the minor changes that give birth to the other complicated type of circumstances which are influential, more striking and highly sensitive to the previous ones. Therefore, the introductory actions have a crucial influence on the progress of the following interrelated affairs, characters' performances and the confusing issues that occur later in the work. Thus, a chain of simple consecutive shifts determines the upcoming evolutionary sequels of behavior in the text, "when they act upon unpredictable initial conditions" (Slethaug, xx). Meanwhile, the high sensitivity is a key common feature of the butterfly effect as well as the Bakhtinian Carnivalesque. Basically, the sensitivity to initial conditions 


\section{Yara Eid Abu El-Manni}

is mostly used as a synonym and an alternative expression of the butterfly effect and illuminates one of the basic characteristics of the Bakhtinian Carnivalesque as well. So, it needs only an unexpected carnivalistic act to turn everything upside down in a literary work. Also, this characteristic conveys the way many vital transitional points derive and stem from a serious unexpected divergence.

In a chaotic system, slight changes do create distinctly different solutions. Thus, all local conditions within a chaotic system can have significant degrees of influence upon a global system. This concept of sensitive dependence causes a significant paradigm shift. Instead of large systems impregnable to small variables, chaos theory allows they can be changed by the influence of very small factors. (Meadows 10)

Moreover, such sensitivity explains how far the most critical moments in a literary work are dictated and ignited, in a hidden way, by the sudden minor conversions that happened earlier and broke up the current order.

Additionally, this unfolds that the literary disorders caused by the huge differences in the course of the work which confirms the occurrence of major changes and alterations. According to Joan Pere Plaza i Font and Dandoy Régis in "Chaos Theory and its Application in Political Science" (2006), "Crises, surprises, sudden and rapid changes, confusions and things out of control prevail in our world and characterize modern organizations and every complex system" (13). Consequently, if the reader cannot perfectly analyze the primitive events, there would be a trouble in understanding the fundamental major changes across the work. So, one should look closely to the beginning and identify what happened in the past to be able to forecast as well as evaluate what is coming next 
in an unstable text. Apparently James Gleick in the prologue of Making a new science (1987) discusses how "tiny differences in input could quickly become overwhelming differences in output" (8). Later, he reaches the point of the way people can "reckon the future of their universe from its initial conditions and the physical laws that guide its evolution" (14). That is why the present researcher asserts on the role played by the first variables in operating the movements of the characters and the mixed changes among the sequences of the actions.

Hence, simple curves in the order of the events serve to shape the complex ideas illustrated and the situations encountered in the text. This is the sensitive pattern that change happens within. Therefore, the Bakhtinian Carnivalesque is considered a diverse series of random events that take place as a reaction to certain unpredictable changes; one sudden change that leads to another in an infinite chain. This goes in agreement with what is reported in Saylor.org; referring to Hamlet as a literary piece overwhelmed and taken over by the chaotic change that stands behind all the unforeseen and startling misfortunes:

The play itself makes use of a version of the famous butterfly effect that would be postulated more than three centuries later: The death of Hamlet's father results, ultimately, in the utter collapse of the entire kingdom of Norway and the death of nearly every major character in the play. The entire world in which Hamlet lives - his entire reality, in fact, both external and internal-is depicted as being radically shifted by the death of a single human being. 
(2)

So, Hamlet is critically a carnivalistic- chaotic masterpiece for all the transitional changes along the events which are already constructed on a primary event that swings everything after it.

Furthermore, each masterpiece is a complex one, especially when the evolution of its futuristic events is subjected to a small initial error. This entails that any scene is well established until it gets sensitive to what just happened before it. Later, it starts effecting the next chain of events one after one. This could be vividly observed in the Shakespearean Hamlet (1603) and Bradbury's "A Sound of Thunder" (1952). In this sense, the present researcher introduces Hamlet as a revolutionary carnivalistic and chaotic piece that is based on a dramatic course of cause and effect, which creates change as a result of the unpredictable actions coming out of sudden initial incidents. This literally makes Hamlet stands as a good example and a fertile site for monitoring how one starting confusing action leads to a twist in the choreography of the play. Moreover, the Shakespearean play presents a synchronized masterpiece of consecutive changes; one change stands as a reason opens the window for another change to happen as a result. This happens in a chaotic pattern since a starting surprising scene acts like the butterfly wing that flutters as well as precedes an infinite series of changes:

This change may happen for unknown reasons, but when minimal changes or "bifurcation points" become "conflict points," they radically transform the subjects and their conditions. For scientists of stochastics, such abrupt change, discontinuity, uncertainty, randomness, and turbulence are the basic forms of natural behavior and may just as easily 
lead to new and amazing possibilities as to negative system disruption or collapse. (Slethaug xxi)

Over the course of the play, Hamlet changes, plans and decides. Sometimes, he hesitates and maneuvers, but at any rate, each of his intriguing actions and dramatic reactions are always provoked by previous drastic scenarios as well as causing a chain reaction of cascading effects.

The play itself is mainly based on the chaos resulted from the tragic unavenged death of King Hamlet, in addition to unintended backstories that helped in the progress of the play:

Hamlet's famous refusal to take any sort of firm action throughout much of the play can be understood as resulting from his intuitive awareness of the chaotic nature of his reality, a reality that appears to be both random and determined at once. Hamlet itself highlights, in miniature, the various seemingly unpredictable and chaotic forces that control reality. (Saylor 2)

Till the end of the play, Hamlet procrastinates and delays his revenge. Some critics justify this due to his suffering from Oedipus complex as he could not kill Claudius because he wishes to be in his place so as to have his mother for himself. Also, may be his religious and intellectual personality prevent him from avenging the death of his father by committing a sin and performing an act of murder:

To be, or not to be, that is the question:

Whether 'tis nobler in the mind to suffer

The slings and arrows of outrageous fortune,

Or to take arms against a sea of troubles

And by opposing end them. To die- to sleep, 


\section{Yara Eid Abu El-Manni}

No more; and by a sleep to say we end

The heart-ache and the thousand natural shocks. (Shakespeare 3.1.55-61)

Likewise, Hamlet takes place in a carnivalistic frame, in which multiple events are not only turned upside down against the regular ordinary rules, but also altered and manipulated due to various bewildering changes. So, this would examine how the Shakespearean masterpiece reflects different and knocking changes; one time it is a change of heart, change of destiny and sometimes it is a change of a man's plan. Therefore, Hamlet is nothing but a group of unexpected results and changing ends because of the previous series of unforeseen causes. Likely, Jacob Fox in "the consequences of inaction" summarizes how Hamlet mirrors the high sensitivity to initial events as "Hamlet's inability to decide whether or not to enact his revenge on Claudius leads to the death of Polonius, the madness of Ophelia, and the eventual downfall of the kingdom of Denmark" (1).

At the very beginning, king Hamlet's abrupt death represents the introductory predicament that affects prince Hamlet in a tragic way and draws him into a deep grief. Besides, his mother's (Gertrude) hasty marriage to his uncle (Claudius) ignites the sensitivity, rage and amazement inside him. After these two initial conditions happened back to back, "Thrift, thrift, Horatio! The funeral baked meats, / did coldly furnish forth the marriage tables" (1.2.179-180), Hamlet feels a change of character as the way he starts to think, analyze and deal with the people surrounding him, including his beloved Ophelia, witnessed a deep change, too. Then, the appearance of the departed king's ghost resembles a carnivalistic tableau that subverts and goes beyond the logical norms. This also functions as another flapping change for the upcoming episodes 
to occur. This surprising presence of the ghost plays a changing line in Hamlet's psychological portrayal. Even his dearest friend (Horatio) was worried that Hamlet's interaction with the ghost could lead to a series of heartbreaking consequences:

Horatio. What if it tempt you toward the flood, my lord,

Or to the dreadful summit of the cliff

That beetles o'er his base into the sea,

And there assume some other horrible form,

Which might deprive your sovereignty of reason

And draw you into madness? Think of it. (1.4.71-77)

However, the ghost's uncovering of the truth and informing Hamlet of his uncle's awful murder, Hamlet becomes aware of that horrible plan, "Upon my secure hour thy uncle stole/ With juice of cursed hebenon in a vial, /And in the porches of my ears did pour /The leperous distilment" (1.5.61-64). These lines are the causes why Hamlet begins to rearrange his future plans and change his attitudes and intentions.

Hence, he decides to fake his madness as a camouflage for preparing for his revenge and achieving his late father's salvation, "The time is out of joint. O cursed spite, /that ever I was born to set it right!" (1.5.190-191). Later, Polonius (Ophelia's father) introduces a subjective analysis upon Hamlet's quite extreme change as Polonius interpreted Hamlet's madness as an aftermath of his wild love to Ophelia, "That we find out the cause of this effect, / Or rather say, the cause of this defect, /For this effect defective comes by cause" (2.2.149-151). In other words, Hamlet's mental status, in Polonius' point of view, was so sensitive to his great love to the beautiful lady whom he was courting, so his major affection for Ophelia is the butterfly wing that caused that madness "Doubt thou the stars are fire, /doubt that the sun doth move, /doubt truth 


\section{Yara Eid Abu El-Manni}

to be a liar, /but never doubt I love" (2.2.113-114). On the contrary, Mother Gertrude used to believe that the king's death is the one and only reason behind Hamlet's insanity, but later she was convinced Polonius' theory, "And for your part, Ophelia, I do wish, /That your good beauties be the happy cause /Of Hamlet's wildness. So shall I hope your virtues/Will bring him to his wonted way again" (3.1.39-42). Subsequently, when Hamlet excels in playing the role of the mad, Claudius decides that "he shall with speed to England/ for the demand of our neglected tribute. / haply the seas and countries different/with variable objects shall expel" (3.1.170-174) as one way of getting rid of Hamlet's craziness and annoyance.

Hamlet is definitely a one artistic unit, in which every fragment stands like a piece of domino with one after and another before; once the first falls, the rest drop down back to back. So, this integrated unit seems to be built upon a peculiar singular incident. In Hamlet, the unfortunate affair of the king's assassination stands behind all the interrupted successive episodes:

In the case of the butterfly effect, if Hamlet were to be able to go back in time and kill Claudius then the lives of many would have been spared. Humans will always have to live with the results of their choices, and many believe everything happens for a reason. Through Hamlet Shakespeare shows how the good and bad of one's choices drive life forward and keep the world spinning. (Fox 3)

While other studies depict Hamlet as an extremely sane and brilliant character, who thinks before managing any step. For instance, after knowing that his uncle is the murderer, he decides to catch him in the act, by watching how he would react to the murder scene, "The play's the 
thing/ wherein I'll catch the conscience of the king" (2.2.566-567). This also assures the high sensitivity that is attributed to how a very small factor intrinsically changes the dynamics of the larger system, "a small rock in the middle of a large river can change the flow dramatically...This small change is causal, but the results are out of proportion to the size and nature of initial conditions... a change from a regular or periodic system to an irregular and aperiodic one" (Slethaug xxii). Significantly, Hamlet's thoughts and mixed feelings grow more and more sensitive to what happens. Indeed, he starts asking himself perplexing questions about life, death, revenge and treason; what is wicked? And what is worthy?

In this we have the behavior where the smallest difference in the beginning of something, no matter how small as long as it is there, will have drastically different outcomes. And herein lies our difficulty with predictability, measurement must be perfect because it lies at the heart of what is significant (Jason Turonie 199).

Hamlet was always thinking whether to take a step forward or another backward. In his complex status, he found himself unable to make a final decision. Moreover, Hamlet is picking his brain about whether to go with or against the flow. He arises a deep inside dispute to answer his subconscious argument if he is going to be able to assassinate his uncle for his treachery, "Am I a coward? /Who calls me "villain"? Breaks my pate across? /Plucks off my beard and blows it in my face? /Tweaks me by the nose? Gives me the lie i' th' throat" (2.2.530-534).

Accordingly, the successive affairs of the play are so sensitive to each other; a change of intention leads to a change of plan which may engenders a change of destiny. In that sense, "a chaotic system is one in 
which small differences in the present state will lead in due time to the largest differences that can occur" (Lorenz 163). For example, the sudden awake of Claudius' guilty consciousness reflects the change of his heart and repentance, as he regrets what he has done to his brother. Especially, after Hamlet asks some actors to perform a play that tells the story of his father's murder. This parody arouses Claudius' ashamed senses and makes his heart softens, "Oh, my offence is rank. It smells to heaven/ it hath the primal eldest curse upon't, /a brother's murder. Pray can I not" (3.3.37-39). When Hamlet takes his sword out, he finds his uncle supplicating. So, seeing him kneeling and praying was the startling incident or the unexpected change of heart that changes Hamlet's scheme to kill him as a revenge. As if he killed his uncle during a religious moment, he would be sending him to heaven instead of hell. This makes Hamlet changes his mind again as a result of that sudden stunning event. Thus, he decides to delay it until he catches him committing a sin:

When he is drunk asleep, or in his rage,

Or in th' incestuous pleasure of his bed,

At game a-swearing, or about some act

That has no relish of salvation in 't-

Then trip him, that his heels may kick at heaven,

And that his soul may be as damned and black. (3.3.90-95)

For the sensitive dependence on the basic events, it is apparently a mutual literary feature between the Butterfly Effect and the Bakhtinian Carnivalesque. This characterization gives privilege to the front line performance which generates the changeable rhythm of the remainder of the work. So, a major piece of advantage goes back to the existence or absence of the destabilized incident at the very beginning that is indirectly responsible for what happens next: 
This horrible plot could've been avoided if Claudius had been killed earlier in the play. Again, if he had died Polonius would have lived and Laertes would not have been seeking revenge and he and Claudius would never have sought to kill Hamlet. Hamlet's actions cause a chain of tragic events to occur that end up killing off the royal family and destroy the kingdom of Denmark. (Fox 3)

Furthermore, the language of the play was also adapted to the continuously transforming episodes, so Shakespeare uses literary linguistic terms that express the changing periodicity.

This is evident in how Shakespeare expresses the theme of the sensitivity to the initial events. The use of some terms that mirror the changeable status from a condition to another. One of these verbs is "wring" which expresses twisting and turning something hold very tightly. Such verb reflects the power and the deep intention of changing a situation. It is also clear among the lines of Hamlet's furious blame to his mother; making her feel responsible for his father's death, "Leave wringing of your hands/ Peace. Sit you down/ And let me wring your heart. For so I shall/If it be made of penetrable stuff" (3.4.35-37). Also, another fierce term like "wag" that means moving repeatedly and quickly from side to side, causing another thing to happen. This one was used by Gertrude while she is quite exclaiming about her son's hurtful and accusing words, "What have I done, that thou darest wag thy tongue/In noise so rude against me?" (3.4.40-41). Consequently, the Shakespearean expressive language helps to enhance the idea of the change as a result of the dramatic high sensitivity to the previous events. It becomes more obvious when Hamlet is interrogating his mother in fury about how she exchanged his passionate and respectable late father with his low and 


\section{Yara Eid Abu El-Manni}

shameful brother as if she was blindfolded by the devil. He provides an extremely descriptive comparison between both men and crying out, "And what judgment/Would step from this to this? Sense sure you have, /Else could you not have motion" (3.4.72-74). Clearly, his terminology helps the reader sense how the change of destiny is evident throughout the ups and downs of the play.

One of these unpredictable moments is when Polonius is eavesdropping behind the tapestry, listening to Hamlet's irrational talk to his mother and suddenly Hamlet feels a third person in the room, so he stabs him with no mercy. Killing Polonius was not at all a part of Hamlet's revenge plan, but it just happened as a collateral damage. Thus, he had mixed feelings of surprise, regret and satisfaction, "Thou wretched, rash, intruding fool, farewell/I took thee for thy better. Take thy fortune. /Thou find'st to be too busy is some danger" (3.4.32-34). The same thing happens when Hamlet was supposed to be assassinated according to a wicked plot in a sealed letter sent to England by Claudius, who decides to get rid of Hamlet's annoyance and intrusion. However, the latter makes a great use of his brilliant wit and replaces the letters and succeeds in changing the lanes of his bloody destiny:

There's letters sealed, and my two schoolfellows,

Whom I will trust as I will adders fanged,

They bear the mandate. They must sweep my way

And marshal me to knavery. Let it work,

But I will delve one yard below their mines,

And blow them at the moon. Oh, 'tis most sweet

When in one line two crafts directly meet. 210,213-215) 
In this way, Hamlet had the dramatic privilege of having the ability to change his luck or destiny from merely being a victim to becoming a triumphant. Unlike other characters who almost loses everything by the end of the play as a result of Hamlet's initial behavior. For instance, Hamlet's madness proved to be somehow contagious since it is one of the factors that drove Ophelia toward losing her mind too.

Hamlet has previously expressed his affection to her and promised her to wed but unfortunately, she was later affected by his extreme sudden change of character and plan by trying to push her away and killing her father as well. So, it is obvious that Shakespeare excelled in illuminating the readers to what extent Hamlet's changed Ophelia from a pretty lady to a mad poor girl, "I hope all will be well. We must be patient, but I /cannot choose but weep, to think they should lay/ him i' th' cold ground. My brother shall know of it" (4.5.42-44). Even Claudius, himself, does not see that coming and sympathized with her, "In huggermugger to inter him. Poor Ophelia/ Divided from herself and her fair judgment, /without the which we are pictures, or mere beasts" (4.5.6062). One single tragic change drives others to happen; just like a sudden back to back flow. No event stands alone by itself, no matter if it is a master scene, a side talk, or a death of a king or a secondary character. This exactly how Slethaug simply elucidates this scientific-literary characteristic:

The sensitive dependence upon initial conditions means that similar phenomena or systems will never be wholly identical and that the results of those small initial changes may be radically different. These unpredictable initial conditions may, for instance, lead to the so-called butterfly effect, in 
which an extremely minor and remote act causes disruptions of a huge magnitude. (xxiii)

In such a way, all events are linked, from the most trivial to the most important, and depending on each other, "When sorrows come, they come not single spies/But in battalions. First, her father slain /Next, your son gone, and he most violent author of his own just remove" (4.5.52-55). That is why Lorenz stresses on how a complete system could be affected as soon as some disturbing stories come into being. For Claudius, despite feeling guiltless of Polonius' death, he is mistaken according to the sensitivity to initial events. He may not be the direct reason, but he is considered one of the consequences of Claudius' act of treason at the very beginning. It is not only Ophelia who got infected by the preceding incidents, but also her brother Laertes who changes from a friend to a foe as a result of his father's death and his sister's lunacy as well as her suicide. Furthermore, Laertes' fit of rage grew even more after Claudius played with his mind; trying to convince him to work Hamlet and kill him in a way that would look like an accident, "Revenge should have no bounds" (4.7.125). For that, Laertes obeys and follows Claudius' blackhearted conspiracy and his heart refuses to forgive Hamlet for his deeds even after his deep confession of his love and real intentions to Ophelia in her funeral, but it was too late.

Later, it seems that change takes place at every single corner in Hamlet, which is ultimately obvious during the fencing challenge. Claudius is startled by a striking change of destiny that he could have never expected. This happens when Gertrude raises the poisoned toast, already makes for Hamlet, and drinks from it as a kind of an enthusiastic hailing to her son, not giving any attention to Claudius' call "Gertrude, do not drink" (5.2.286). Thus, after Laertes manages to scratch Hamlet with 
the poisoned blade, everything turns upside down when Hamlets picks Laertes' own sword and slashes him back with it. At this moment, Laertes confesses to Hamlet and asks him for forgiveness:

The treacherous instrument is in thy hand,

Unbated and envenomed. The foul practice

Hath turned itself on me. Lo, here I lie,

Never to rise again. Thy mother's poisoned.

I can no more. The king, the king's to blame. (5.2.312-315)

Once Laertes finishes his words, uncovering Claudius' murderous plot, Hamlet rushes at his uncle and kills him. In spite of being the mastermind from the starting point, Claudius ends up as a dead body. He has metaphorically played the carnivalistic starting point which upturns and reverses the situations since the dawn of the play. Claudius is somehow like Cain who committed the first murder by killing his brother Abel as his motives were envy and anger. Up till now, all killing in the world is considered a consequence of that primitive slaughter.

Similarly, Claudius's homicide stands at the butterfly wing that generates the dramatic unrest till the end. Also, it is known that Claudius killed his brother king Hamlet, but this sole incident threw down all the chess pieces which result in the death of the other characters in the play as hamlet whispers at last, "the rest is silence"(5.2.356). Therefore, Horatio finds himself agitated for being the last man standing so, he tries to commit suicide by drinking what is left of Gertrude but Hamlet begged him not to do it, so as to live for telling his cautionary tale. Hence, Fortinbras, looking at the dead royal bodies on the floor, takes the crown for himself. Obviously, various analyses mark out that Hamlet's indecisive deeds represent the direct and the indirect cause behind the deaths of six characters, including himself. Furthermore, "Reading 


\section{Yara Eid Abu El-Manni}

Shakespeare's Hamlet with a firm knowledge of chaos theory serves to reveal a surprising measure of awareness on Shakespeare's part of the forces that control reality, an awareness that predates the scholarly exploration of chaos theory by nearly four centuries" (Saylor 3).

Accordingly, one of the different methods to decode Hamlet, as a chaotic- carnivalistic piece, is analyzing the changing identity of this tragedy through its acts and scenes. This is mainly why the present writer focuses on how studying the overwhelming dramatic change is prominent for further realization of the text, since the "nonlinear systems are, then, extremely sensitive to initial conditions; each iteration of the system increases the magnitude of the initial perturbation; and there are certain parameters or boundaries to the phenomena and certain ways in which one pattern unpredictably follows another" (Slethaug xxiii). Also, Theodor Pavlopoulos in "The terrible turn of events- Literature and the butterfly effect" applies the Butterfly Effect as a literary phenomenon that could help the critic to rediscover the literary outline that is ruled by the genesis of the primary occurrences since "every minuscule act, every tiny event, every single word uttered, even every breath taken might unsuspectedly activate a long chain of irreversible effects, each one inevitably triggered by its previous and which, in the long run, might grow to a catastrophic outcome. (1)

Laughter, as a carnivalistic feature of change, embraces multiple events in Hamlet so as to relieve the serious tone of anger, stress and revenge that prevails the text. In addition to ridiculing the oppressive atmosphere. This comic element supports the theme of change and keeps it spinning beyond the lines. Thus, Alexander Crawford in "Hamlet's 
Humor: The Wit of Shakespeare's Prince of Denmark" investigates the function of humor in revolutionizing the play:

Shakespeare was too good a judge of character and of human nature to mingle such humor with madness. He has given Hamlet nearly all varieties of humor, from the playful to the sardonic. Speaking of the king, Hamlet's humor is caustic and satirical. To Polonius and the other spies, he is playful and contemptuous. In the graveyard over the skulls he is sardonic and pathetic, and over Yorick's he is melancholy. In all alike he is sane and thoughtful. (9)

Critically speaking, Shakespeare's mixed irony and humor elevate the play's chaotic-carnivalistic change within extremely tragic extracts like the graveyard scene. In this one, Hamlet digs in his deep pathetic sorrows and it displays his own idea of death. However, his humorous wit is always present even in the darkest times:

There's another. Why may not that be the skull of a lawyer? Where be his quiddities now, his quillities, his cases, his tenures, and his tricks? Why does he suffer this rude knave now to knock him about the sconce with a dirty shovel and will not tell him of his action of battery? Hum! (5.1.82-87)

Likewise, Hamlet sometimes changes and contradicts himself within a comic frame for mocking somebody he despises in an implicit way.

So, laughter endorses Hamlet to master that psychological game. This is clear enough when he starts acting like a fool in his meeting with Polonius; as he insults him first then, in a second, he praises him. This illogical contravention produces laughter and consequently change, "Hamlet: Excellent well. You are a fishmonger. / Polonius: Not I, my 
lord. / Hamlet: Then I would you were so honest a man" (2.2.166-169). Hamlet's clever hoax makes everyone around him wonder if he is truly gone mad or he is just pretending; all of this confusion is due to his bitter sweet humor and change of attitude. Moreover, Hamlet's battle of wit and excellent fancy is intertwined and extended in his patter that is somehow contagious and accelerates from one scene to another along the tragedy, "This unfailing humor that toys with life's comedies and tragedies alike does not come from madness, but from sanity and selfpossession. This should make certain the real soundness as well as the great fertility of Hamlet's mind. Humor and madness do not travel the same road" (Crawford 9). Hence, Shakespeare's humor sometimes pushes the literary change ahead, since it reflects the character's swinging mood and its effect on others. As a result, the Shakespearean carnivalistic drama is apparently built on a chaotic scene that may seem haphazard to the reader before it becomes obvious how it controls the whole masterpiece. The first phase of change, which is the high sensitivity to the early events of the text, is noticeably a shared literary feature between the Butterfly Effect and the Carnivalesque. Thanks to such a critical aspect, further attention is drawn towards the gravity of the simplest components in a work.

On the other side, Ray Bradbury's "A Sound of Thunder" (1952) displays a literary chart of changing causes and effects woven in extremely sensitive and nonlinear passages. This short story also shows the changing effect of the past on the future and how this works in a dependent chain of aftereffects. Similarly, Peter Hyam's movie A Sound of Thunder (2005), adapted on Bradbury's work, supposes that change happens as a result of the sensitivity to the inceptive episodes. In the intro of his movie, Hyam focuses on "a new technology invented that 
could change the world or destroy it". This explains how the impact of change is a double-edged weapon, as the butterfly effect turns up infinitely in the short story.

Bradbury sets the events of his Sci-Fi short story in 2055, on the eve of an American presidential elections between a fascist and a moderate candidate: Deutscher and Keith respectively, that ended with the winning of Keith. Moreover, "A Sound of Thunder" takes place in a time when technology in America reaches its peak. It goes around a group of rich business men who are interested in travelling back in time so they buy tickets at a time-safari corporation so as to enjoy shooting Dinosaurs six million years ago, "Christ isn't born yet," said Travis, "Moses has not gone to the mountains to talk with God. The Pyramids are still in the earth, waiting to be cut out and put up. Remember that. Alexander, Caesar, Napoleon, Hitler - none of them exists" (Bradbury 2). These dinosaurs they were going to shoot, were about to die anyway, so they reach them two minutes before their death. Unfortunately, the rich gentlemen, due to awkward disturbances, they lose their temper and did not stick to the strict rules put by the scientific team led by Travis. On top of these rules are no straying off the floating path and no shooting before Travis' word. When they return back home, they realize that disastrous alterations and devastating changes happened and later they realized that all of these horrible fluctuations resulted from squashing an ancient butterfly, "Suffice it to say that all actions have consequences big and small" (Taylor 5).

At every single corner of the short story, the butterfly effect is evident asserting on how the unexpected changes of the future are extremely sensitive to the initial present events, so Bradbury sheds light on the pre-chaotic situation so as to give the reader a complete frame of 


\section{Yara Eid Abu El-Manni}

what happened before the journey to be able to measure the differences in the aftermath; using the conditional if clauses:

If the election had gone badly yesterday, I might be here now running away from the results. Thank God Keith won. He'll make a fine President of the United States...If Deutscher had gotten in, we'd have the worst kind of dictatorship. There's an antieverything man for you, a militarist, anti-Christ, antihuman, antiintellectual...Anyway, Keith's President now. (Bradbury 1)

In this sense, change is in the air of this masterpiece because it is all about the chaotic transgression and the carnivalistic transformation among the events of the short story. Bradbury shows how the scientists as well as the rich moguls go astray in order to trespass the canonical order of time and place. At the same time, they turn a blind eye to the crucial results that could affect the future in a profound way and lead to annihilation, "We don't want to change the Future. We don't belong here in the Past... Not knowing it, we might kill an important animal, a small bird, a roach, a flower even, thus destroying an important link in a growing species" (Bradbury 3). Thus, Travis later summarizes it in a simple way, to help them figure out that any simple mistake could ignite extreme mutations:

Say we accidentally kill one mouse here. That means all the future families of this one particular mouse are destroyed, right?" ...Step on a mouse and you crush the Pyramids. Step on a mouse and you leave your print, like a Grand Canyon, across Eternity. Queen Elizabeth might never be born, Washington might not cross the Delaware, there might never be a United States at all. So be careful. Stay on the Path. Never step off! (Bradbury 3) 
Bradbury scientifically manifests the striking but unnoticed proof of the highly dependence on the primary influences. He translated it into a suspenseful literary framework. He even applied the critical feature on a carnivalistic nonlinear flashback to illustrate the powerful echo of the sensitivity.

Additionally, the hyper sensitivity to the initial random events frequently ties those early random incidents to their later large- scale changes. A small perturbation takes place and a tornado of excessive underlying actions would follow. This gives rise to a vivid text full of non-deterministic adjustments. Therefore, Bradbury crystalizes a logical scientific equation during the mutual dialogues among the characters, expressing their deep beliefs. The equation can be set as follows; One mouse is killed \{the initial condition\} the death of ten foxes $\Rightarrow$ the starvation of a lion $\Rightarrow$ a group of cavemen die $\Rightarrow$ the entire human race would be eradicated. That is why it is worthy to mention that, Hyam, in his movie, created a character "Dr. Sonia Rand", who opposes the time jumps so as to educate as well as alarm the audience of this technology's awful consequences, because if we kept messing with our past, the future is going to be ruined at a certain moment. In a literary piece, a character's short-lived momentary would definitely modify his or other's serendipity:

The idea of a universe where small or even seemingly negligible events may in the long run greatly and unpredictably affect the future was before Lorenz brought forward by various writers as a philosophical curiosity, a paradox or an attempt to understand what is commonly reffered [sic] to as destiny...this uncertainty caused by the minuscule imperfections, gave birth to a potential of 


\section{Yara Eid Abu El-Manni}

dangers, imaginary or not, a fear of some terrible turn of events that might be triggered and arise out of the unimportant. (Pavlopoulos 3)

Since they were completely aware of that, the team took every possible precaution in order to assure that no change would go down in the prehistoric atmosphere. They believe that they could have every single thing under control, but they totally forgot that no one can tame the nonlinear sensitivity of change as it is highly sensitive and unpredictable:

Perhaps only a soft breath, a whisper, a hair, pollen on the air, such a slight, slight change that unless you looked close you wouldn't see it. Who knows?... we're being careful. This Machine, this Path, your clothing and bodies, were sterilized, as you know, before the journey. We wear these oxygen helmets so we can't introduce our bacteria into an ancient atmosphere. (Bradbury 4)

These distinguished precautions could not stand between the action, no matter how minimal and meek it could be, and its reaction. Sometimes the latter could even exceed the first, so this whole process, whether socially or literary, is complex and super-delicate as well.

A. Taylor, in his review on Bradbury's short story, clarifies that Bradbury's work serves not only to entertain but also to speculate on the dangers of time travel. This is due to his illustration of the fluctuating falls caused by a seemingly unrelated events over a long period of time, is not only demonstrated at the climax of the story, but also explained in the context of the story, "While Bradbury does an excellent job illustrating the point, he tends to over simplify the ripple effect since he assumes the timeline to be static and that by removing the mouse from the equation a void is created that multiplies up the timeline" (1). Immediately, the 
moment the team come back home, they sense the aroma of change, they could note that there is something weird going on:

Eckels stood smelling of the air, and there was a thing to the air, a chemical taint so subtle, so slight, that only a faint cry of his subliminal senses warned him it was there. The colors, white, grey, blue, orange, in the wall, in the furniture, in the sky beyond the window, were . . . were ...And there was a feel. His flesh twitched. His hands twitched. He stood drinking the oddness with the pores of his body... What sort of world it was now, there was no telling? He could feel them moving there, beyond the walls, almost, like so many chess pieces blown in a dry wind. (9)

These wide-range changes extend in seconds to the language on the signs, walls and everywhere to a strange complicated one, none of the group could understand it or what truly happened in their absence. They even got more amazed when they linked it to the remains of a dead butterfly in the dirt of Eckels' shoes. This left him dazed. Despite becoming aware of the reason, his mid is not able to solve this entangling dilemma. The human mind could not digest all of this frenzy madness at once:

No, it can't be. Not a little thing like that. No!... "Not a little thing like that! Not a butterfly!" cried Eckels... a small thing that could upset balances and knock down a line of small dominoes and then big dominoes and then gigantic dominoes, all down the years across Time... Killing one butterfly couldn't be that important! Could it? (10)

These infinite series of changes do not stop at the point of language but it goes further than that to reach out to the destiny of the nation in the hands of its politicians, "Who - who won the presidential election 
yesterday?" The man behind the desk laughed. "You joking? You know very well. Deutscher, of course! Who else? Not that fool weakling Keith. We got an iron man now, a man with guts!"(10). And here comes the moaning regret of man over his mistakes and his foolish and reckless stamps; wishing that he could turn back the hands of time to gain back his comfort zone or his world as it used to be before he destroys it, "Can't we," he pleaded to the world, to himself, to the officials, to the Machine, "can't we take it back, can't we make it alive again? Can't we start over? Can't we-"(10). Travis could not take it anymore as his remorse was much bigger than he could grasp so he fired his rifle with a sound of thunder. In this respect, Bradbury intentionally sketches out a cycle of unintentional coincidences within a streamline of fluid changes that could gradually lead to shattering and catastrophic scenes.

In general terms, tracking down change in "A Sound of Thunder" is one medium to pursue a critique upon the development of the intense chaotic-carnivalistic incidents. Thus, the study of the story's dependence on the previous events could be regarded as the cleverest agent of change. Once the critic gets the author's gist and assemble the shreds, sooner or later the phenomenon of change "becomes, fundamentally, an act of coauthoring in which desires and aspirations are transposed" (Muayyad Jabri 9). Seemingly, the inner transformations and the escalation of events in Shakespeare's Hamlet and Bradbury's "A sound of Thunder" are subordinated to the focal theme of change as it is the pivot round that their fictional worlds revolve. Moreover, these literary works given the force of change can develop, transcend and regenerate.

Besides, Paul Warren, in his poem "The Butterfly Effect", summarizes that force of change by explaining what would happen if we could turn back the hands of time and change to fix or prevent somethings 
from happening in the past. Showing how these simple retouches would utterly change our future:

If you could change the past

How would you do it to make it last

Each step that you take will influence other things

And so unintended consequences will be what it brings

They call it the butterfly effect

And it suggests what you would expect

When a movement of air by a butterfly's wings

Will cause a hurricane in another place as it rings. (1-8)

Furthermore, he artistically applies the scientific- based theory on famous historical events to argue how far our present time politics is definitely the payoff harvest of yesterday's decisions. Therefore, today's verdicts, judgments and choices shape the approaching destiny of the nations. In this respect, Warren's lines exhibit that the current chaotic behavior arises from a prior carnivalistic madness. His perspective revolves around the way the modern time tragedies and the lack of order in any political system are immensely dependent on the previous complicated conditions. Moreover, the influence of a critical change in the past cannot be erased as it would last for a very long time:

I wonder what would happen if you were able to kill Hitler

Would there have been a Second World War there

Or would it mean that we fought the Russians instead

As Stalin and the Communist Russians were those to dread

In 1961 could we prevent the assassination of Kennedy there

Would he have escalated the Viet Nam War for us to beware

Of fighting the Communists with China and Russian Armies 
And maybe the Third World War would be the end for the Allies. (916)

Warren offers an analytic carnivalistic treatment of social, political and historical worlds turned upside down due to the Bakhtinian chaotic logic of how only one modified literary rule could overturn a realm into another direction.

Overall, each of Hamlet and "A Sound of Thunder" is "a space that encapsulates an entire world of carnivalesque follies and a topsy-turvy world of misadventures, chaos, and chance encounters" (Horacio Rivero 1). Both the Butterfly effect and the Bakhtinian carnivalesque, throughout common literary traits, celebrate change as a phenomenon that provides critics and readers with new interpretations and perceptions of a text. This chaotic carnivalistic power of change is literary buttered by their mutual high sensitivity and dependence on the initial events. Besides, a chaotic- carnivalistic reading of a literary work depicts how one change at the opening of a text changes all. Moreover, a critical analysis of Hamlet and "A Sound of Thunder" crystallizes that the heart of both texts is occupied by change:

Rather than seeing change as a phenomenon outside selfhood, change conceived in terms of shifting identities is a shifting phenomenon because of the variety in utterances and the fluidity and dispersion... whereby things are enriched by insights being brought to bear on the handling of change from more than one angle. (Jabri 9)

That is because change in Shakespeare's Hamlet and Bradbury's "A Sound of Thunder" is reflected in a string of temporary inversions that are highly sensitive to each other. So, the present researcher associates change with the chaotic-carnivalistic sensitive dependence on the 
elementary events. Consequently, each action frequently plays the role of a reason for one time and a result in another time. This also illuminates the way a literary text is a combination of subsequent events that unpredictably echo the primary performance or scene. Therefore, such a phenomenon actually assists in the dramatic growth of the work and fuels it with change from the rebellious opening scene to the finale.

Commenting on the significance of change in a literary work, it is noted that there is a duality between the growth of interest into the text and the escalation of the serial changes. This would happen since change empowers both the plot and the themes of the masterpiece. Besides, it provides dissimilar choices and conveniences over the course of the literary corpse. Moreover, when there is a near possibility for a new change, it helps to unveil multiple corners of the work. This is why, in this paper, it is promoting to theorize change as a literary technique to study a literary piece far and wide for advanced critical views. Besides, each unpredicted change reconstructs and reshapes the story and takes it to a brand new level of criticism. Jabri, hence, explains how Bakhtin supports change and challenges the idea of having only one explanation for each literary work, "For Bakhtin, no single interpretation, meaning, or definition of an identity achieved through narrative can stand as more than a momentary manifestation" (7). This also reinforces the hypothesis that change, as a part and parcel of the Butterfly Effect and the Bakhtinian Carnivalesque can be inclined as a literary phenomenon that makes any critical study much more resonant. 


\section{Yara Eid Abu El-Manni}

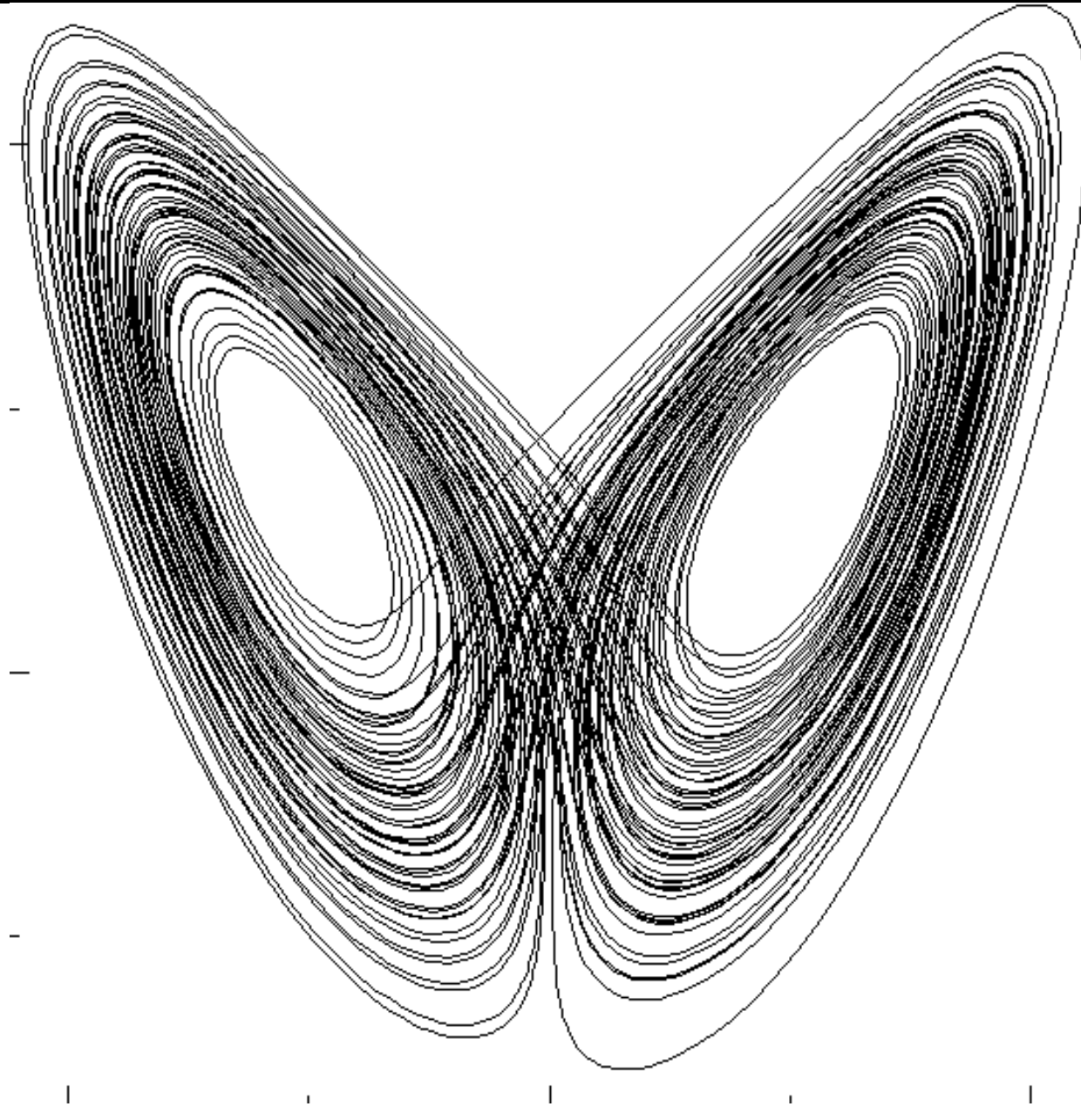

Figure 1

Lorenz's strange Attractor 


\section{Works Cited}

Bakhtin, Mikhail. Rabelais and His World. Trans. by Helene Iswolsky. Bloomington: Indiana University Press, 1984.print

Baldwin, Karen. Prod. A Sound of Thunder. Screenplay by Gregory Poirier. Dir. Peter Hyams. Perf. Ben Kingsley and Edward Burns. North Carolina, 2005.Film

Bradbury, Ray. “A Sound of Thunder.” New York: Harper Collins, 1952.print “Carnivalesque.” oxfordreference.com. Oxford Reference, 21 Jan. 2014. Web. 7 May. 2015.

Crawford, Alexander W. Hamlet, an ideal prince, and other essays in Shakespearean interpretation: Hamlet; Merchant of Venice; Othello; King Lear. Boston R.G. Badger, 1916. Shakespeare Online. 20 Aug. 2009.

$$
\text { (9April. }
$$

<http://www.shakespeareonline.com/plays/hamlet/humourhamlet.html $>$.

Crichlow, Michaeline A., and Piers Armstrong. "Carnival praxis, carnivalesque strategies and Atlantic interstices." Journal for the Study of Race, Nation and Culture Vol.16 (2010): 399-414.print

Dentith, Simon. Bakhtinian Thought. New York: Routledge, 1995.print

Fig. 1. Lorenz Strange Attractor, hitfoundry.com, 19 Dec. 2015, http://www.hitfoundry.com/issue_07/mmm_lfo.htm 


\section{Yara Eid Abu El-Manni}

Font, Joan Pere Plaza I, and Dandoy Régis." Chaos Theory and its Application in Political Science". Beyond Linearity: Research Methods and Complex Social Phenomena (July 2012) .print

Fox, Jacob. "The Consequences of Inaction." Honors English 12(Dec.2013):14.

Ghys, Étienne. "The butterfly effect." The Proceedings of the 12th International Congress on Mathematical Education. Springer International Publishing, 2015: 19-39.print

Gleick, James. Chaos: Making a new Science. London: Penguin Books, 1987.print

Gossin, Pamela. Encyclopedia of Literature and Science. London: Greenwood, 2002.print

Harty, John Francis. Oscillation in Literary Modernism. Switzerland: Peter Lang, 2009.print

Jabri, Muayyad. "Change as shifting identities: a dialogic perspective." Journal of Organizational Change Management 17.6 (2004): 566-577.print

Laplace, Pierre Simon. Philosophical Essay on Probabilities. Trans.by Andrew I Dale. New York: Springer, 1995.print

Lorenz, Edward N. The Essence of Chaos. London: University of Washington Press, 1995.print

McCarthy, Cameron, and Greg Dimitriadis. Reading and Teaching the Postcolonial: From Baldwin to Basquiat and Beyond. New York: Teachers College Press, 2001.print 
Meadows, Martin Thomas. Literary Canon as a Dynamic System of Chaos and Complexity Theory. Diss. Oklahoma State University, 2006.print

Parker, Alyson Jo. Narrative Form and Chaos Theory in Sterne, Proust, Woolf and Faulkner. New York: Palgrave Macmillan, 2007.print

Pavlopoulos, Theodore. "The terrible turn of events - Literature and the butterfly effect." The peacock's tail, 2013, pavlopoulos.wordpress.com/2013/01/05/the-terrible-turn-of-eventsliterature-and-the-butterfly-effect. Accessed 14Nov.2016.

Ramani, Anusha Uthaman. "The Carnivalesque in Steinbeck's Tortilla Flat and Rushdie's Midnight's Children." Steinbeck Review 9.2 (2012): 8993.print

Rivero, Horacio. "Don Quixote in His Labyrinth: Carnivalesque Folly, Lust, and Chaos at the Inn.” Neophilologus (Dec.2007): 627-640.print

Robinson, Andrew. "In Theory Bakhtin: Dialogism, Polyphony and Heteroglossia.” Ceasefire Magazine July 29, 2011.print

Schutzman, Mady. "Guru Clown, or Pedagogy of the Carnivalesque." Theatre Topics 12.1 (March 2002): 63-84. print

Shakespeare, William. Hamlet. New York: Penguin Books, 1999. Print.

Slethaug, Gordon E. Beautiful Chaos: Chaos Theory and Metachaotics in Recent American Fiction. Albany: New York Press, 2000.

Sprott, J. C. "Simplifications of the Lorenz Attractor." Nonlinear Dynamics, Psychology, and Life Sciences 13. 3(2009):271-278. Print

Stewart, George. Storm. Berkeley: Heyday Books, 1941.print 


\section{Yara Eid Abu El-Manni}

Sullivan, Paul, Mark Smith, and Eugene Matusov. "Bakhtin, Socrates and the carnivalesque in education." New Ideas in Psychology 27.3 (2009): 326342. Print

Taylor. A. "Time Travel Short Story Review." Andy Anachronisms,2004, timetravelreviews.com/shorts/sound_of_thunder_short.html. Accessed 23 Aug. 2016.print

The Saylor Foundation. "Chaos Theory as Literary Theory.” Saylor.org. Saylor Academy ENGL301Unit 8.1.3 Assignment. Feb.2012: 1-3 Web. 16 Nov. 2015.

Turonie, Jason. "Chaos Theory, a suggestion toward deterministic reality." University of Wisconsin-La Crosse (2002): 185-210.print

Warren, Paul. “The Butterfly Effect.” Poemhunter.n.d. Web. 9 March 2016.

Weichselbaumer, Doris. "Sex, romance and the carnivalesque between female tourists and Caribbean men." Tourism Management Vol.33(Oct.2012): 1220-1229.print 
